\title{
Notas para uma teologia do Espírito
}

\section{Notes for a theology of the ofpirit}

Antonio Manzatto*

Resumo: 0 presente artigo enumera alguns princípios fundamentais para a elaboração de uma pneumatologia, e o faz em forma de notas. Destaca a necessidade de uma reflexão teológica contextualizada e consequente, e enumera os pontos de destaque que devem fazer parte de uma Teologia do Espírito atualizada.

Palavras-chave: Espírito Santo, Pneumatologia, Missão, Jesus Cristo.

Abstract: This article enumerates some basic principles for the drafting of a pneumatology, and does so in the form of notes. Highlights the need for a contextualized and consequent theological reflection, and lists the highlights that should be part of a Theology of the Spirit updated.

Keywords: Holy Spirit, Pneumatology, Mission, Jesus Christ

\section{Introdução}

Pensar o Espírito Santo deve sempre ser feito a partir do contexto, o que significa fazer teologia situada. A situação vivida pela humanidade é determinante no fazer teológico, sobretudo porque a teologia deve ser atual, isto é, contemplar os problemas contemporâneos colocados à fé de maneira a permanecer compreensível à humanidade contemporânea; e deve ser salutar, isto é, significar salvação para a humanidade de hoje. Daí a necessidade de pensar o Espírito Santo na atualidade, em sua ação hoje na vida da Igreja.

* Doutor em Teologia pela Universidade de Lovaina, Bélgica; professor de teologia do Programa de Estudos Pós Graduados em Teologia da PUC/SP. 


\section{Introdução}

Fazemos aqui pequeno destaque de alguns pontos que fazem parte do patrimônio teológico universal, pontos e temas que, certo, já são do conhecimento de todos mas que, evidenciados, ao menos proporcionam bases sólidas para repensar a pneumatologia na época e no contexto atual.

\section{0 Espírito de Jesus}

O Espírito procede do Pai e do Filho, dizemos nós no credo. Do Pai, origem sem princípio, e do Filho, que para nós é Jesus. Aqui se focaliza toda a insistência na ligação do Espírito Santo com a pessoa de Jesus. O projeto de Jesus é o projeto do Pai, o Reino de Deus. Assim, a causa defendida por Jesus é a mesma causa do Pai. Não há oposição entre o Pai e Jesus; ao contrário, como diz João, o Filho e o Pai não são senão um (Jo 10,30) embora não o mesmo.

Este mesmo ponto deve ser destacado com relação ao Espírito Santo. Não há solução de continuidade entre a ação do Filho e a ação do Espírito, embora não sejam o mesmo. O Espírito não tem outro projeto que não o projeto de Jesus, ele que assumiu o projeto do Pai. Aqui se entende, pois, quando afirmamos a igualdade fundamental que une o Pai, o Filho e o Espírito Santo, já que esse Espírito recebe a mesma adoração e a mesma glorificação devida ao Pai e ao Filho. O que o Espírito busca não é diferente do que o Filho busca: realizar o Reino do Pai.

É por isso que Paulo nos lembra que só no Espírito podemos reconhecer Jesus como Senhor e podemos segui-lo pelos caminhos da história (1Cor 12,3). Nesse sentido, o Espírito é memória e atualização do caminho de Jesus, além de ser garantia de fidelidade ao mesmo projeto. Só no Espírito podemos seguir Jesus, e não fora dele. No Espírito, não podemos ser infiéis ao Senhor e a seu projeto para a história e a humanidade. Não há seguimento de Jesus sem o caminhar na presença do Espírito; e não há caminhar na presença do Espírito se não for para seguir os passos de Jesus de Nazaré. 
Este ponto nos impede de cair, por exemplo, no perigo que rondou Joaquim de Fiore e seu pensamento de que há três eras: a do Pai, o Antigo Testamento, a do Filho, o Novo Testamento, e a do Espírito, a era da Igreja. Isso poderia nos levar a pensar que viver na presença do Espírito não traz as mesmas exigências ou não conduz ao mesmo caminho do seguimento de Jesus. Tal seguimento teria, concede-se, implicações políticas, de reforma da sociedade e de compromisso com os empobrecidos. Já andar na presença do Espírito não traria esse incômodo: bastaria um sentimento individual de uma espiritualidade acomodada, tranquila, que falasse de paz e harmonia, sem os conflitos da construção da história.

Ora, o Espírito Santo é o “continuador” da obra de Jesus, o que significa que optar pelo Espírito é optar por Jesus e pelo seu caminho de construção da fraternidade através da entrega e da preocupação com os excluídos deste mundo. Outro tipo de opção ou comportamento não seria, propriamente, vivência no Espírito Santo de Deus.

\section{0 Espírito Consolador}

No entanto, o Espírito não é Jesus. O Espírito não se encarnou, ele é outra pessoa. Sua maneira de agir na história, na construção do projeto do Pai, não é a mesma maneira do Filho Encarnado.

Jesus, ao falar do Espírito, segundo João, fala de uma outra pessoa, o Paráclito (Jo 14,16; 16,13). A tradução e compreensão dessa palavra, paráclito, pode ser de fundamental importância para a teologia. Na tradução da Septuaginta, o verbo correspondente à palavra paráclito é usado para traduzir o verbo hebraico que significa consolar. Assim, no início do Segundo Isaías, encontramos aquelas palavras: consolai, consolai meu povo (parakaleite, parakaleite ton laon mou) (Is 40,1).

Porém, há que bem compreender-se o que significa consolar. Não é simplesmente ter dó, ter pena, dar tapinha nas costas, pedir para conformar-se com a situação presente. Consolar é, sim, ter compaixão, viver com-paixão; nessa mesma linha situa-se a misericórdia, deixar o coração encher-se da miséria do outro.

Assim sendo, a consolação liga-se ao sentido tradicional da palavra paráclito em grego, que significa advogado, defensor. O paráclito é 
aquele que defende, que advoga, ou seja, que assume como sua a causa do pobre, do miserável, daquele de quem se tem compaixão, daquele que precisa de consolação. Assim, portanto, como diz Gutierrez, ${ }^{1}$ consolar é libertar, porque é assumir a causa do pobre. O Paráclito é aquele que defende o pobre e torna-nos capazes de assumir a causa de Jesus, que é a mesma causa do Pai, que é a causa do pobre: vida e liberdade.

Consolar é lutar contra a situação presente de opressão e injustiça. Consolar, e é essa a ação do Espírito, é abrir possibilidades do novo, de uma outra maneira de viver: a vida em liberdade, em igualdade, em comunhão. Por isso é que o Espírito renova a face da terra, faz novas todas as coisas, como diz o Apocalipse (Ap 21,5). Esse renovar não é simplesmente tornar novo o coração, mas tornar novo o mundo onde se vive, possibilitar relações humanas baseadas na justiça e na fraternidade. Não se trata, pois, de um novo qualquer, de qualquer novidade como gosta de nos desenhar o sistema neoliberal. 0 novo aqui, a novidade, a boa-nova, é o tornar o mundo cada vez mais parecido com o sonho de Deus. Esse o sentido de, no credo, dizermos que o Espírito Santo é quem "falou pelos profetas".

E isso só pode advir pela ação dos que não estão satisfeitos com o atual estado de coisas, com a atual organização do mundo, uma vez que aqueles para quem tudo está ótimo não vão querer comprometer-se com transformações do mundo. Isso só pode advir pela ação dos pobres. Uma ação que não é solitária, apenas deles, mas sim de aliança vivida com o Espírito Santo de Deus. E aqui o Espírito Santo revela-nos seu nome: ele é a força dos fracos.

\section{0 Espírito de Vida}

Outra afirmação que fazemos no Credo a respeito do Espírito Santo é a de dizermos que ele é o Senhor que dá a Vida. "Creio no Espírito Santo, Senhor que dá a Vida”, dizemos nós. Os textos bíblicos referentes a esta fé são abundantes. Já no Antigo Testamento percebemos isso,

1 Cf. Gustavo Gutierrez, Beber em seu próprio poço, São Paulo: Loyola, 2000. 
quando, na criação, o “Espírito pairava sobre as águas” (Gn 1,2); o ser humano adquire vida quando recebe o sopro divino (Gn 2,7), a ruah divina, da mesma ruah que pairava sobre as águas (a palavra hebraica para sopro é a mesma que para Espírito).

O Espírito que anima a missão de Jesus, que está presente na vida de Jesus desde a sua concepção, é o mesmo que ele entrega aos apóstolos quando João nos conta que "Jesus soprou sobre eles dizendo: recebei o Espírito Santo” (Jo 20,22). E a missão de Jesus, como nos lembra o mesmo João, é dar "a todos vida, e vida em abundância" (Jo 10,10). O Espírito Santo é quem dá a Vida. Por isso o chamamos de Espírito Vivificador. Sendo assim, a ação do Espírito coloca-se em sintonia com a missão de Jesus, como se destacou no primeiro ponto, e também com a realidade de vida dos pobres de nosso mundo, como afirmado no segundo ponto desta reflexão.

Com efeito, os pobres de nosso mundo estão condenados à morte. O sistema promete que acabará com a pobreza, e talvez o faça; só que a maneira dele terminar com a pobreza é matando os pobres. Aliás, nem os chamamos mais de pobres, mas de excluídos: excluídos do sistema, da economia, das decisões políticas, das benesses da sociedade, da educação: eles estão excluídos da vida, condenados à morte pela violência, pela droga, pelas epidemias, pela fome.

Dizer que o Espírito dá a Vida não é apenas dizer que ele dá a Vida Eterna. Também isso, evidentemente. Mas para se chegar à Vida Eterna é preciso ter a Vida humana. E é o mesmo Espírito quem dá a vida humana. Ele não a dá, simplesmente, e depois vai embora, como se não tivesse mais nada a ver com a humanidade. O Espírito que gera vida a gera constantemente e a defende. A defesa da vida é obra do Espírito, sobretudo a defesa da vida ameaçada; seja a defesa da vida da criação (animais e vegetais que teimamos em destruir) ou seja a defesa da vida do humano fraco, ameaçado, explorado, excluído.

A pergunta que muitas vezes ronda nossas cabeças é a de saber onde age o Espírito Santo. Quais seriam os critérios que nos permitiriam dizer onde se situa a ação do Espírito Santo, e onde se situa a ação do outro espírito.

Pois bem, o critério fundamental para distinguirmos a ação do Espírito Santo é a Vida. Onde há defesa e promoção da vida, lá está o 
Espírito Santo de Deus. E é por isso que Medellín, Puebla e Aparecida são sinais da presença do Espírito Santo na vida da Igreja latino-americana. Onde a vida não é defendida nem promovida, não pode haver presença do Espírito Santo. A pergunta não deve ser aquela de saber onde está o Espírito Santo, ou se tal ou tal ação pertence ou não a ele. A pergunta deve ser a de saber onde há defesa e promoção da Vida, ou se tal ou tal ação promove e defende a vida ou não. Se não há defesa e promoção da vida, se tal ação promove a morte, evidentemente isto não pode vir do Espírito Santo. Mas se há defesa e promoção da vida, se tal ação ou iniciativa promove e defende a vida da humanidade, claro está que isto só pode vir do Espírito Santo, e seria mesmo um pecado (pecado contra o Espírito, talvez) perguntar de onde ela vem.

\section{0 Espírito Missionário}

É esta a missão a que o Espírito conduz a igreja de Jesus. Que a igreja seja fundamentalmente missionária, todos temos consciência, sobretudo depois do Documento de Aparecida. Ali os bispos latino-americanos lembram a natureza missionária da igreja, decorrente do próprio encontro com Jesus. Assim como o Pai me enviou eu também vos envio, diz o Evangelho de João (Jo 20,21), quando Jesus concede o Espírito Santo aos apóstolos. As duas coisas vão, assim, juntas: a entrega do Espírito e o mandato missionário, de modo que a missão passa a ser constitutiva do próprio ser eclesial. Não há igreja que não seja missionária, que não esteja pronta a proclamar a Boa-Notícia de Jesus.

Por outro lado, o que seja a missão, o documento de Aparecida também já disse e nos ajudou a compreender. A missão não é simples proclamação religiosa, ela não se resume a angariar audiência para atos e gestos religiosos. Bem mais do que isso, o que importa para Jesus é o mundo novo que o Reino inaugura. Assim, o Espírito Santo, que preside a missão, conduz a Igreja a esta ação de propor e criar um mundo novo, de justiça e igualdade, onde possa haver vida para todos.

Cabe lembrar dois pontos, com base na Escritura. O primeiro é que o Espírito preside a ação de Jesus. Ele está presente em toda a vida de Jesus, e os evangelhos assinalam sua presença na concepção, 
no início do ministério, na cruz e na instalação da Igreja (Lc 1,35; Mt 3,17; Jo 19,30; At 2). O Espírito que conduz o seguidor de Jesus é o mesmo que conduziu a vida e a ação do Mestre, e por isso o discípulo é capaz de seguir Jesus, de atualizá-lo e de viver como ele, com Espírito. O segundo ponto está na certidão de nascimento da Igreja, como costumamos falar do relato de Pentecostes. Que o Espírito envia em missão o texto deixa bem claro, já que os discípulos superam o medo dos judeus e vão para a praça anunciar Jesus. Mas o texto deixa claro, também, o resultado da missão, já que a multidão que crê se torna um só coração e uma só alma, tornando-se capaz de partilhar a vida e os bens (At 2,42-47).

A missão que o Espírito suscita e dirige é a que promove o Reino de Deus, transformando o mundo em lugar de paz e união, não por medidas autoritárias, pregações ideológicas ou procedimentos miraculosos, mas pela instalação da justiça e da fraternidade. Mudar o mundo é a missão dos seguidores de Jesus; permear o mundo com os valores do Evangelho, eis a missão a que o Espírito envia. E como Ele não é dirigido pelas estruturas eclesiais, sopra onde quer, mostrando as sementes do verbo presentes nas culturas oprimidas e nas maneiras de estabelecer a justiça e paz no meio da humanidade.

\section{Para concluir}

Por fim, cabe lembrar um último ponto. Preocupamos-nos sempre em saber, e talvez com razão, quem é e como é o Espírito Santo. Dizemos sempre que ele é ação de Deus, amor de Deus, força de Deus etc., querendo caracterizá-lo. No entanto esta nossa caracterização tende sempre a uma espécie de pessoalização estrita: pensar o Espírito Santo em si, em seu ser pessoal, em sua ontologia enfim, ressaltando como ele é ou deve ser. Isso pode ser perigoso para a teologia, sobretudo porque tendemos a concluir o estudo de sua pessoa quando se caracteriza seu ser, nem sempre olhando para sua ação.

E é exatamente por isso que ao falarmos do Espírito Santo damos muita importância à palavra Espírito, porque ela indica uma maneira de ser de Deus (não raro opomos Espírito à matéria, no molde gnóstico,) 
e porque ela indica uma de nossas preocupações fundamentais de cristãos: a espiritualidade.

O grande problema, e aí o perigo desta ontologização, é que derivamos uma espiritualidade da palavra espírito. E esquecemo-nos que o que caracteriza fundamentalmente Deus não é a palavra Espírito, mas a palavra seguinte: Santo. Deus não é simplesmente espírito, Deus é Santo. E do Espírito Santo dizemos mais ainda: que ele é Santificador, que ele nos torna santos.

É daí que devemos derivar uma espiritualidade consequente, aquela preocupação de viver no Espírito, de andar na sua presença: da santificação a que o Espírito conduz. Isso significa que, por um lado, afirmamos que o Espírito revela-se como é em agindo, através de sua ação (e assim atende-se ao legítimo desejo e mesmo à obrigação teológica de entender como Deus é: Deus é assim porque age assim, nunca vive-versa). Mas significa também, e esta uma consequência fundamental, que a vida no Espírito engloba uma ética.

Ser santo, claro, não é obedecer simplesmente a preceitos morais, mais ou menos difíceis. A santidade não se mede por obediência a preceitos ou por quantidade de atos de piedade religiosa. Mas santidade não é também fazer o que se quer, ou seguir simplesmente impulsos. A ética é fundamental. E a palavra ética indica matriz de comportamento, com claro alcance social. O Espírito Santo nos conduz à santificação, isto é, nos coloca no caminho de determinada ética.

Curioso notar que, apesar disso, muitos movimentos pentecostais ou neopentecostais, de corte evangélico ou católico, não enfatizam nenhuma ética, o que corresponde absolutamente à proposta do mercado. Com frequência, as práticas e as propostas são medidas pelo interesse despertado, pelo faturamento (em dinheiro ou em audiência, o que vem a dar no mesmo), e não pela ética. Vale o que é consumido, seja bom ou não; perguntar se é bom ou não é secundário; em teologia, isso significaria que perguntar se é salutar ou não seria secundário: vale o que o povo quer, o que o povo gosta (ou o que se acha que o povo quer e que o povo gosta). O critério para estabelecimento da verdade, aqui, torna-se não o Evangelho, mas a audiência, a popularidade. Vale o consumo. Seria possível atribuir isso ao Espírito Santo de Deus? 
Ora, o Espírito Santo conduz, sim, a um tipo de comportamento que contrasta com o sistema vigente. Por isso andar na presença do Espírito não é consumir produtos religiosos; não é simplesmente cumprir preceitos; não é ter experiências intimistas que confortem o ego; não é esperar nem deixar o Espírito agir sem que eu nada faça; não é entregar apenas o coração para Jesus; não é fazer grandes milagres ou maravilhas, nem falar em línguas. Curioso notar que a insistência nos milagres, nos grandes feitos, nos dons especiais, não é senão destacar a força e os privilégios. O poder de Deus e do intermediário é que são destacados nos milagres e nos dons especiais. A insistência é sobretudo no poder. A isso corresponde uma teologia do império, ou da prosperidade, em perfeito acordo com o sistema neoliberal: vale quem é forte, inclusive política e religiosamente; vale quem tem privilégios, inclusive política e religiosamente. Quase uma “teologia de resultados”, para lembrar a terminologia do futebol. Ora, o Espírito Santo não é força dos fortes. O Espírito Santo é força dos fracos, que dá força ao fraco para confundir o forte. A tentação do poder e sua teologia correspondente continuam a causar problemas na vida dos cristãos.

O que é, então, andar na presença do Espírito? Qual a matriz de nossa espiritualidade? Segundo os critérios de discernimento da presença do Espírito apontados acima, andar na presença do Espírito Santo de Deus é compadecer-se e lutar pela libertação dos pobres; é promover e defender a vida, sobretudo onde ela se encontra ameaçada. Isso é viver na presença do Espírito, porque o Espírito Santo é Vida e Misericórdia, como nos ensinou Jesus de Nazaré e como ele demonstrou em sua vida.

\section{Bibliografia}

MANZATTO, Antonio; PASSOS, J. Décio; MONNERAT, José Flávio. A força dos pequenos, São Paulo: Paulus, 2013.

GUTIERREZ, GUSTAVO. Beber em seu próprio poço, São Paulo: Loyola, 2000. SMAIL, Tom, A pessoa do Espírito Santo, São Paulo: Loyola, 1998. CONGAR, Yves, Je crois en l'Esprit Saint, Paris: Cerf, 1995. 